\title{
USOS Y PERCEPCIÓN DEL DOMINIO DE FACEBOOK EN ESTUDIANTES DE PSICOLOGÍA EN SU MODALIDAD A DISTANCIA DE UNA UNIVERSIDAD PÚBLICA
}

\author{
Oscar Iván Negrete Rodríguez y Claudia Lucy Saucedo Ramos \\ Universidad Nacional Autónoma de México \\ México
}

\begin{abstract}
RESUMEN
El objetivo de la presente investigación fue conocer la percepción de dominio y los usos de facebook en estudiantes de Psicología en su modalidad distancia de una universidad pública. Participaron 172 estudiantes (134 mujeres y 38 hombres) que cursaban materias de los últimos tres semestres de la carrera (séptimo, octavo o noveno). En los resultados encontramos un nivel de edad entre 21 a 70 años, y la mayoría de los estudiantes estaba en la condición de adulto joven o adulto. Respecto de su uso de facebook, encontramos que hay una variabilidad en los tiempos destinados al mismo, así como en el uso que se le da, ya sea con fines de ocio, para actividades académicas y para asuntos de sus empleos. La mayoría de los estudiantes (37\%) se percibe como moderadamente competentes en el uso de la red social. Concluimos que facebook representa una herramienta más que utilizan para combinar metas de ocio, demandas académicas y laborales. Los resultados coinciden con lo indicado por Cortés (2015), quien piensa que los usuarios de facebook usan esta red para comunicarse con amigos o como actividad secundaria mientras desarrollan actividades escolares.
\end{abstract}

Palabras Clave:

usos de Facebook, dominio de Facebook, educación a distancia, psicología, estudiantes universitarios.

\section{USES AND PERCEPTION OF THE DOMAIN OF FACEBOOK IN STUDENTS IN PSYCHOLOGY IN IT'S DISTANCE MODALITY FROM A PUBLIC UNIVERSITY}

\begin{abstract}
The purpose of this research was to know the perception of domain and the uses of Facebook in Online Psychology students of a mexican public university. 172 students ( 134 women and 38 men) who attended the last three semesters of their degree (seventh, eighth or ninth) participated. According to the results, student's age varied from 21 to 70 years, and most of them are located in a young-adult category. Regarding to the use of Facebook, we find that there is a big variability in the time that students dedicate to it, as well as in the use that is given, either for leisure purposes, for academic activities and for employment issues. Most of the students perceived theirselves as moderately competent in the use of this social network. We conclude that Facebook represents another tool that online students use to combine leisure goals, academic and labor demands. Our results coincide with those indicated by Cortés (2015) who describes that Facebook users use this network to communicate with friends or as a secondary activity while doing school activities.
\end{abstract}

Keywords:

Facebook uses, Facebook domain, e-learning, psychology. university students.

Bitácora del Artículo:

| Recibido: 5 de marzo de 2020 | Aceptado: 23 de Junio de 2020 | Publicado en línea: Julio-Diciembre de 2020 | 


\title{
USOS Y PERCEPCIÓN DEL DOMINIO DE FACEBOOK EN ESTUDIANTES EN PSICOLOGÍA EN SU MODALIDAD A DISTANCIA DE UNA UNIVERSIDAD PÚBLICA
}

\author{
Oscar Iván Negrete Rodríguez y Claudia Lucy Saucedo Ramos \\ Universidad Nacional Autónoma de México \\ México
}

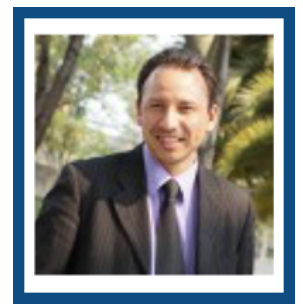

Oscar Iván Negrete Rodríguez

FES Iztacala, UNAM

Correo: ivan.negrete@iztacala.unam.mx

Profesor de Asignatura A, Facultad de Estudios Superiores Iztacala. Doctorando en Psicología Social y Ambiental, por el Programa de Maestría y Doctorado de la UNAM. Su línea de investigación versa en autoeficacia, interacción en ecosistemas digitales y uso de las TIC en estudiantes en modalidades abiertas y a distancia.

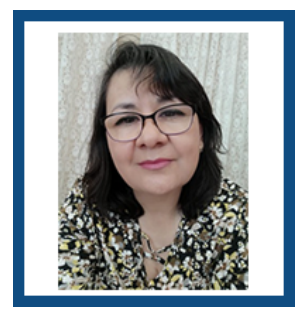

Claudia Lucy Saucedo Ramos

FES Iztacala, UNAM

Correo: csclusar@gmail.com

Profesora titular de la carrera de Psicología de la FES Iztacala. Doctora en Investigaciones Educativas, Departamento de Investigaciones Educativas, Cinvestav. Miembro del Sistema Nacional de Investigadores Nivel I. Miembro del Consejo Mexicano de Investigación Educativa, A. C. (COMIE).

\section{CONTRIBUCIÓN DE LOS AUtORES}

Oscar Iván Negrete Rodríguez desarrolló los planteamientos originales de la investigación, recolección, análisis e interpretación de la información recopilada. Elaboró el primer borrador del artículo. I Claudia Lucy Saucedo Ramos asesoró la elaboración del proyecto de investigación y las etapas conducentes. Co-construyó con el primer autor la elaboración del artículo, destacando los aspectos conceptuales, de análisis de datos, de estructura del artículo y aportaciones del mismo.

\section{AGRADECIMIENTOS}

Los autores agradecen a la Coordinación de Educación a Distancia de la Facultad de Estudios Superiores Iztacala las facilidades proporcionadas para el presente estudio. La investigación aquí reportada forma parte del proyecto de doctorado del primer autor.

\section{DATOS DE FiLIACIÓN DE LOS AUtORES}

Facultad de Estudios Superiores Iztacala, UNAM

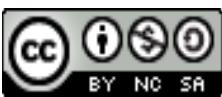

Copyright: (c) 2020 Negrete-Rodríguez, O.I: \& Saucedo-Ramos, C.L.

Este es un artículo de acceso abierto distribuido bajo los términos de la licencia Creative Commons Reconocimiento-NoComercial 4.0 Internacional, por lo que su contenido gráfico y escrito se puede compartir, copiar y redistribuir total o parcialmente sin necesidad de permiso expreso de sus autores con la única condición de que no se puede usar con fines directamente comerciales y los términos legales de cualquier trabajo derivado deben ser los mismos que se expresan en la presente declaración. La única condición es que se cite la fuente con referencia a la Revista Digital Internacional de Psicología y Ciencia Social y a sus autores. 


\section{TABLA DE CONTENIDO}

INTRODUCCIÓN

MÉTODO

Participantes, 283

Instrumento, 283

Procedimiento, 283

RESULTAdos

283

Discusión

REFERENCIAS

293

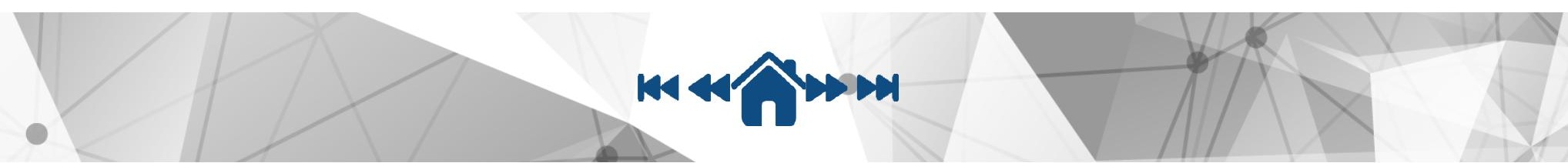




\section{INTRODUCCIÓN}

$\mathrm{E}$ grado de avance que ha tenido la tecnología en la actualidad ha transformado de manera considerable las posibilidades y modos en que los individuos se conocen, trabajan, se comunican y aprenden. Hoy los procesos de globalización y el comercio online conllevan a que la sociedad se denomine como la sociedad de la información y la comunicación, en la que toman fuerza la educación virtual, el aprendizaje en línea y el blended-learning; esto gracias a la confluencia de tres factores: los avances en la ciencia, los desarrollos tecnológicos y las demandas actuales de la sociedad (Herrera-Batista, 2009).

Es así que encontramos un entorno que se caracteriza por constantes cambios relacionados con el uso de las tecnologías de la información y comunicación (TIC) en las diversas situaciones, actividades y relaciones en que participan las personas. Esta condición impacta en la dinámica y los resultados del proceso de enseñanza-aprendizaje, debido a que la tecnología se torna una herramienta de apoyo imprescindible. Así, las TIC pueden ser utilizadas para asistir el proceso de enseñanza-aprendizaje de maneras diversas, al incentivar nuevos métodos de búsqueda de información, al fomentar el aprendizaje colaborativo en los escenarios virtuales, y al permitir compartir ideas y experiencias (Bachiller, 2013), entre otras tantas, en función de los contenidos, los objetivos e incluso las preferencias y creatividad del docente.

Antes de continuar es importante delimitar las TIC como herramientas tecnológicas que permiten la creación, innovación, difusión y gestión del conocimiento por medios informáticos, con el objetivo de solventar las necesidades de los individuos, independientemente de su nivel de desarrollo, educación o profesión.

En este sentido podemos afirmar que las TIC facilitan la comunicación entre los miembros de la sociedad, en procesos diversos, en las prácticas de enseñanza-aprendizaje y en la difusión de actividades diversas (Martínez y Raposo, 2006; Hubach, 2013). Por lo anterior, han sido integradas al proceso educativo demandando a gobiernos e instituciones relacionadas con la educación la necesidad de asignar presupuesto para el mantenimiento y adquisición de equipos de tecnología diversa (Herrera-Batista, 2009).

Con los avances en las TIC han surgido nuevas y variadas opciones de comunicación que pueden ser usadas por los individuos en distintos contextos y con diferentes intenciones; esto no es ajeno al caso de las redes sociales por internet. Judge y Robbins (2009) consideran que las redes sociales son una de las áreas en que más ha impactado la tecnología, citando como ejemplos a Myspace y Facebook. Mediante estos sitios las escuelas, compañías, organizaciones, asociaciones, grupos e individuos se ponen en contacto con sus clientes, colegas, seguidores, amigos, familiares y con quienes les interesa establecer comunicación, manteniéndolos informados, promociones, creaciones, actividades o nuevos productos.

Hoy la mayoría de los estudiantes universitarios usan las redes sociales virtuales con diferentes objetivos: lúdicos, socialización, búsqueda de información, integración a grupos, participación en redes e informativos, entre otros. Se afirma que los estudiantes tienen conocimiento de la función didáctica que puede tener el internet y sus herramientas al permitir compartir materiales, opiniones y/o conocimientos. El uso cotidiano de estas herramientas permite que los estudiantes se hayan habituado a estar en todo momento frente a una computadora, una consola de videojuegos, música digital, dispositivos móviles y distintas tecnologías con conexión a la red (Cortés, 2015).

Hablar de redes sociales por internet o redes sociales virtuales hace referencia a un ecosistema virtual; son son escenarios que ofrecen la oportunidad de interactuar de modo social a partir de intercambios dinámicos entre los usuarios de la red, quienes pueden tener gustos, necesidades y características similares (Sánchez y Arroyo-Cañada, 2016). Para Cheung, Chiu y Lee (2011) las redes sociales por internet son comunidades virtuales por medio de las cuales sus usuarios se relacionan y comunican, coincidiendo en objetivos específicos y temporales en muchos casos. De esta manera, es viable afirmar que las redes sociales propician el desarrollo de nuevas dinámicas de interacción y la generación de nuevos códigos de interacción, colaboración y cooperación entre sus usuarios.

Respecto a la preferencia de los usuarios por determinada red social se ha encontrado que las más populares en internet usadas por estudiantes de nivel superior son Facebook (32\%), YouTube (25\%) Twitter (16\%) e Instagram $(12 \%)$, mientras que otras redes sociales por internet concentraron el $15 \%$ restante. Es interesante que, en esta misma línea, se reporta que los estudiantes de nivel superior consideran como una red social a la aplicación de mensajería instantánea denominada WhatsApps (Cortés, 2015).

Lo anterior coincide con los hallazgos de otras investigaciones en las que participan estudiantes de nivel superior (Gómez, Roses y Farias, 2012; González, Lleixà y Espuny, 2016), cuyos hallazgos refieren que la mayoría de los estudiantes eran usuarios de por lo menos dos redes sociales, siendo las más populares Tuenti, Facebook y Twitter, formando una parte de su vida cotidiana, ya que 
de $87.3 \%$ de los estudiantes de nivel superior, $66 \%$ la usa diariamente, y $21.3 \%$ reportó usarla bastante (González et al., 2016). Por su parte, Abúndez, Fernández, Meza y Alamo (2015) afirman que la red social más popular y completa a nivel mundial es Facebook.

Además de lo relativo al uso de las redes sociales en un panorama más abierto, existen investigaciones que las posicionan como herramientas importantes en las labores académicas al apoyar en la formación de los estudiantes, incluso ofrecen la posibilidad de promover una cultura digital de la cual también se apropian padres y profesores. En este sentido, se afirma que cuando las redes sociales se usan de manera correcta incrementan la productividad y el rendimiento de los estudiantes, pero, en caso de no ser así, atentan contra el desarrollo de las habilidades académicas, como cuando los usuarios se apropian de errores para el análisis de la información y la redacción (Abúndez et al., 2015).

Es así que las redes sociales, como Facebook, pueden ser un apoyo en la educación al permitir el trabajo colaborativo, el aprendizaje individual, la retroalimentación en grupo o en pares, una mejor retención de lo aprendido y potencializar las experiencias de los alumnos que las usan (Espuny, González, Lleixà y Gisbert, 2011). Sin embargo, a pesar del conocimiento que tienen los estudiantes acerca de las redes sociales, sus expectativas de su uso con fines académicos son escasas.

En el caso de Facebook, se identificó que es una herramienta digital que conforma una comunidad virtual integrada por diversas culturas, idiomas, ideologías, religiones, rasgos étnicos, etarios y sociales, convirtiéndose en la red social más usada a nivel mundial. A pesar de lo anterior, muchos usuarios de Facebook opinan que sólo es una red digital que permite conocer y contactar a personas en internet, aunque su estructura es más compleja de lo que parece, pues al combinar distintas herramientas ofrece una amplia variedad de funciones, como enviar mensajes privados, publicar mensajes en los muros de los contactos, ser una fuente de información personal, crear álbumes de fotografías con capacidad ilimitada, grabar y publicar vídeos, crear grupos, escribir y compartir notas (como un blog), crear eventos e invitar a asistentes potenciales e integrar otras aplicaciones (González y Delgado, 2015).

Respecto a la investigación que se ha efectuado acerca de los usos de Facebook, Espuny et al., (2011) desarrollaron un estudio en el cual se pretendía indentificar el conocimiento y aprovechamiento que los estudiantes de nivel superior dan a las redes sociales. Sus resultados reportan que Facebook es la red más popular, siendo percibida como la de mayor utilidad didáctica porque permite compartir do- cumentos en diversos formatos (audio, vídeo, texto e imagen). Por su parte, Gallo, Mora y Rozo (2013) indican que es necesario analizar el uso formal o institucional de las redes sociales como parte de un proceso de interacción orientada al proceso de enseñanza-aprendizaje. En esta línea se encuentra el Proyecto Facebook desarrollado en la Universidad de Buenos Aires, cuyo objetivo fue construir un entorno colaborativo y abierto de educación. Dentro de los logros obtenidos por dicho proyecto se informa que, más allá de la transmisión de conocimiento, fue posible promover el trabajo colaborativo entre pares y permitir que ese conocimiento pudiera salir del aula al hacer uso de la red social (Adaime, 2015).

Por otro lado, la investigación realizada por Gómez, et al. (2012), orientada a conocer los motivos más recurrentes por los cuales los estudiantes hacen uso de Facebook, encontró que el $75 \%$ de sus participantes lo hacen para para estar al tanto de lo que ocurre en su entorno social, el $61.8 \%$ por entretenimiento y el $24.7 \%$ por algún motivo escolar. Las actividades más comunes que mencionaron los participantes fueron: reunirse con los amigos en línea, conocer lo que pasa con sus grupos de amigos o comentar las fotos, vídeos o comentarios de sus contactos. González y Saucedo (2020), por otra parte, encontraron que los estudiantes universitarios concretaban diversos procedimientos por medio de Facebook para trabajar con sus compañeros en la elaboración de trabajos académicos. Se demostró que Facebook no era una herramienta sólo para socializar con amistades, sino que los estudiantes lo usaban para enviar documentos, abrir chats para ponerse de acuerdo, estar al tanto de los tiempos en que cada uno entraba en línea para trabajar juntos, mandar mensajes para apresurar la elaboración del trabajo en curso, estar en contacto con las instrucciones de los docentes, etcétera.

Por otro lado, podemos observar que hay investigación orientada a explorar, conocer y describir el uso de las TIC en la educación, e indican que se les ha encasillado en su aspecto tecnológico, siendo estudiada sólo como un apoyo para el docente y con un amplio uso social por parte del estudiantado. A pesar de lo anterior, no por ello se pierden de vista los usos que pueden tener en el proceso de enseñanza-aprendizaje al ser un elemento importante en el desarrollo de la sociedad actual, sin considerar que las opciones de comunicación representan un recurso didáctico al incidir en diversos procesos cognitivos (Badillo, 2012).

Como hemos visto, las TIC se consideran ya herramientas fundamentales para el desempeño académico y social de los estudiantes universitarios. Aún más en el caso de los estudiantes universitarios inscritos en una modalidad a distancia; se esperaría que desarrollen habilidades esenciales para el uso de TIC porque es con ellas que 
concretarán su participación en planes y programas académicos y en actividades diversas de carácter formativo. Según García (2017), cada vez más la educación en línea tiene grandes ventajas, no sólo para los estudiantes inscritos en programas a distancia, sino también los de sistema presencial. Es mediante conferencias en línea, plataformas de aprendizaje, comunidades de aprendizaje, aprendizaje mixto, etcétera, que se logra un ajuste de los planes de enseñanza a la heterogeneidad estudiantil respecto a tiempos de acceso a las clases y contenidos en línea, tipos de uso de las ofertas académicas, lugar donde radican los estudiantes, economía con que cuentan para continuar sus estudios y tipos de aparatos para entrar en contacto con la información digital, entre otros aspectos.

Así, Artavia y Castro (2019) enlistan el conjunto de estrategias didácticas que estarían a disposición de aprendizajes y desempeños en línea: Moodle (sistema de administración de contenidos), presentación de contenidos (tutoriales, videos, presentaciones didácticas), co-construcción (wikis, blog, foros en línea), autoría y productividad (almacenamiento, creación de documentos, creación de audios, creación de lenguajes educativos), comunicación (chats y videoconferencias), inmersión (simuladores, realidad virtual), estrategias de aprendizaje (mapas mentales, toma de notas) y herramientas cognitivas (hojas de cálculo, presentaciones, textos y gráficos). Estos autores indican que algunas estrategias son más usadas que otras, y que hay tendencia a reproducir las clases cara a cara en una dimensión de clases en línea.

Para los estudiantes a distancia hay retos importantes porque muchos de ellos tienen una edad promedio de 30 años, son casados, con hijos y con empleos que les dejan pocas horas para acceder al desarrollo de trabajos académicos. De ahí que las herramientas móviles les permiten conectarse en diferentes momentos y lugares.

Se da por supuesto que el estudiante a distancia deberá desarrollar competencias para el manejo de herramientas online, tanto las asociadas con actividades pedagógicas propuestas en cada plan de estudio, como las que les permitirán conectividad y trabajo colaborativo. En consecuencia, existe el supuesto de que el estudiante a distancia debe tener mayor independencia, autonomía y organización de las actividades, y el desarrollo de capacidades de afrontamiento para combatir el estrés que el conjunto de tareas le demandan (Vega, Gómez, Gálvez y Rodríguez, 2017).

No obstante, según Amaya y Rincón (2017) no siempre el estudiante a distancia logra la autorregulación académica que se necesitaría, porque en el estudio de estos autores se encontró que los estudiantes a distancia tienden a trabajar sólo bajo presión, son dependientes de las instrucciones de los docentes, tienen escasa tolerancia a la frustración y difi- cultades para gestionar su propio aprendizaje. En este sentido, habría que preguntarse si es que logran desarrollar o no competencias básicas para el manejo de las TIC que les permitan sostener su aprendizaje en línea.

Por su parte, Chiecher (2019) argumenta que para entender el éxito académico en estudiantes de modalidad a distancia no basta con que dominen determinadas TIC, sino que es necesario que haya una fuerte presencia docente que acompañe el rumbo de trabajo del alumnado; que el estudiante cuente con la ayuda de compañeros y de la propia institución, y que también tengan autorregulación para el aprendizaje, así como asumir los resultados en función de atribuciones internas, como el esfuerzo y la dedicación que se despliega.

Por otro lado, las tabletas y los teléfonos celulares se han reconocido como herramientas importantes que son usadas por el estudiantado para desarrollar sus actividades académicas. Según Agila, Ramírez, García y Samaniego (2017), los estudiantes a distancia utilizan estos recursos para gestionar material de lectura, acceder a plataformas escolares y como buscadores de información. Estos autores consideran que en los planes educativos se debe contemplar cómo los estudiantes a distancia tienen que ir más allá de estas competencias digitales para lograr la producción y edición de contenidos, es decir, lograr aprendizajes significativos.

Para puntualizar, las redes sociales tienen una amplia popularidad al ser una herramienta usada para trasmitir o intercambiar información de manera rápida, sencilla y cómoda. Las TIC tienen un enorme potencial porque al ser usadas los estudiantes pueden lograr aprendizajes significativos y participar de modo activo en las tareas académicas que tienen, muchas de las cuales ya les demandan un desempeño en línea. El estudiante universitario en la modalidad a distancia debe dominar diversas TIC para desarrollar tareas académicas en tiempos, espacios y estilos de aprendizaje diversos. Este es un supuesto que es necesario probar. Por ello, en la presente investigación identificaremos elementos del perfil socioeconómico de una muestra de estudiantes universitarios inscritos en la modalidad a distancia en la carrera de Psicología, con el objetivo de analizar sus percepciones del uso y domino que tienen de Facebook, tanto en el terreno de lo académico como en otros campos de aplicación.

La revisión de la literatura indica que la mayoría de los estudios orientados a conocer la experiencia e interacción de los estudiantes en Facebook han desarrollado análisis cuantitativos (análisis factoriales de los instrumentos o análisis de frecuencias de las respuestas), que si bien han arrojado información valiosa, no permiten conocer en palabras de los estudiantes cuál 
es su experiencia al interactuar con las redes sociales, qué problemas enfrentan, cómo los solucionan, cómo facilitan o entorpecen sus actividades escolares, sobre todo en el caso de los estudiantes de nivel superior en un modelo a distancia. A partir lo anterior, en la presente investigación nos planteamos como objetivo conocer la percepción de dominio y los usos de Facebook en estudiantes de Psicología en la modalidad a distancia de una universidad pública.

\section{MÉTodo}

La presente investigación fue de carácter exploratorio y se desarrolló con una muestra intencional con participación voluntaria (Hernández, Fernández y Baptista, 2014), seleccionada a partir de un conjunto de estudiantes de la carrera de Psicología inscritos en la modalidad a distancia.

\section{Participantes}

En el estudio participaron 172 estudiantes -134 mujeres $(77.9 \%)$ y 38 hombres $(22.1 \%)$ - de las generaciones 2010 a 2016, de la licenciatura en Psicología en la modalidad a distancia, impartida en una universidad pública de México. Estos estudiantes se encontraban cursando materias de los últimos tres semestres (séptimo, octavo o noveno). Los participantes contestaron una encuesta en línea con datos demográficos, académicos, laborales y relativos al uso de Facebook (tiempo, dominio y actividades efectuadas).

\section{Instrumento}

La encuesta aplicada era un formulario de Google documents, herramienta abierta que permite elaborar cuestionarios y encuestas en línea. La encuesta estaba conformada por 22 ítems que permitieron recabar información acerca de los estudiantes en torno a los siguientes aspectos: sexo, edad, lugar de residencia, semestre, promedio, estado civil, generación de ingreso a la universidad, número de hijos, edades de los hijos, ocupación, horas dedicadas a actividades escolares, horas dedicadas a actividades del hogar y horas dedicadas a actividades laborales. Respecto al uso de Facebook se consideraron las preguntas relativas al tipo de actividades: ¿en qué lo usan?, ¿cómo fue que lo empezaron a usar?, ¿cuántas veces al día ingresan? y, tiempo que dedican a interactuar en este ecosistema digital. La encuesta consideró preguntas abiertas y de selección de respuesta cerrada. Para la elaboración del instrumento se tuvo en cuenta lo reportado en la literatura con relación al uso y características de Facebook, así como al perfil de los estudiantes en línea.

\section{Procedimiento}

Los investigadores establecieron comunicación con la coordinación de la Licenciatura de Psicología en la modalidad a distancia. Describieron el objetivo del estudio y solicitaron apoyo para distribuir entre sus alumnos vía correo electrónico- la invitación para participar en el estudio y las instrucciones para proceder. Se invitó a participar en la investigación a los 592 alumnos inscritos en los tres últimos semestres de la licenciatura (184 de séptimo semestre, 241 de octavo semestre y 167 de noveno semestre). En el correo se aclaró que la información que proporcionarían en caso de aceptar participar sería confidencial y usada con fines académicos y científicos. En caso de aceptar tenían que hacer clic en un enlace que los llevaba al formulario de la encuesta.

\section{Resultados}

La información cuantitativa recopilada por la encuesta fue procesada con ayuda del SPSS-IBM versión 20.0 haciendo análisis de frecuencias y análisis descriptivos, obteniendo medidas de tendencia central, histogramas de frecuencia, medidas de dispersión y gráficas de barras.

De las 592 invitaciones enviadas por correo, 172 estudiantes contestaron el instrumento; 134 participantes fueron mujeres $(77.9 \%)$ y 38 hombres $(22.1 \%)$, con un rango de edad de 21 a 70 años, siendo la edad promedio 40.36 años, con una desviación estándar de 11.2, lo cual indica que $68.6 \%$ de los participantes tiene una edad de entre los 29.16 y los 51.56 años. La edad que predominó en los participantes fue de 36 años. Sólo 10\% de los participantes tuvo menos de los 26 años (figura 1).

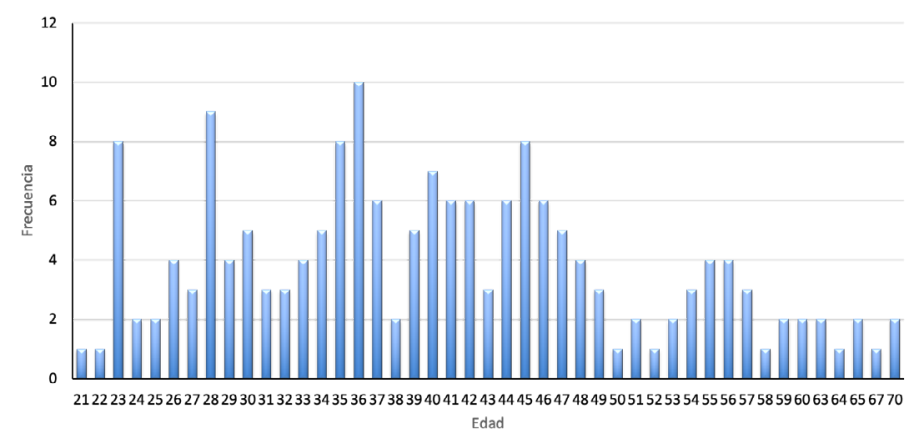

Figura 1.

Histograma de frecuencia de la edad de los participantes.

Al reflexionar acerca de los grupos de edad en función de las etapas de desarrollo encontramos en la muestra que están inscritos jóvenes (menores de 31 años), adultos jóvenes (de 31 a 45 años), adultos (de 46 a 60 años) y adultos mayores (mayores de 60 años). Los 
datos indican que la mayoría de los estudiantes inscritos en la carrera son adultos jóvenes (48\%), seguido del grupo de adultos $(25 \%)$, después jóvenes $(23 \%)$, y al final los adultos mayores (5\%). De acuerdo con lo anterior, los estudios a distancia ofrecen opciones para continuar formándose sobre todo a la población con edad menor a los 45 años, población que busca una certificación escolar para mejorar laboralmente.

Respecto del lugar de residencia, los estudiantes viven en distintos estados de la República Mexicana, predominando la Ciudad de México y el Estado de México, que concentran a $60.8 \%$ de los participantes, seguidos de Oaxaca (7.6\%), Tlaxcala (5.3) y Puebla (4.7). De modo que, aunque se observa una presencia a nivel nacional, e incluso en el extranjero (un participante reportó residir en España), los estudiantes se concentran en el área metropolitana.

La variabilidad en la edad y en los lugares de residencia son aspectos que, según García (2017), quedan cubiertos de manera favorable por el sistema de educación a distancia porque se contempla la inclusión de diversos tipos de estudiantes, el apoyo a su economía al no tener que trasladarse, la flexibilidad en tiempo para el trabajo académico, y la ubicuidad, ya que al participar online se puede estudiar desde diferentes lugares.

$\mathrm{Al}$ analizar el promedio de calificaciones de los participantes identificamos una media de 8.7, con una desviación estándar de 0.5 , siendo el promedio 8 . Con base en estos valores podemos afirmar que se reporta un buen rendimiento académico en la mayoría de los estudiantes. En la figura 2 se muestra el histograma de frecuencia relativo al promedio de calificaciones de los alumnos.

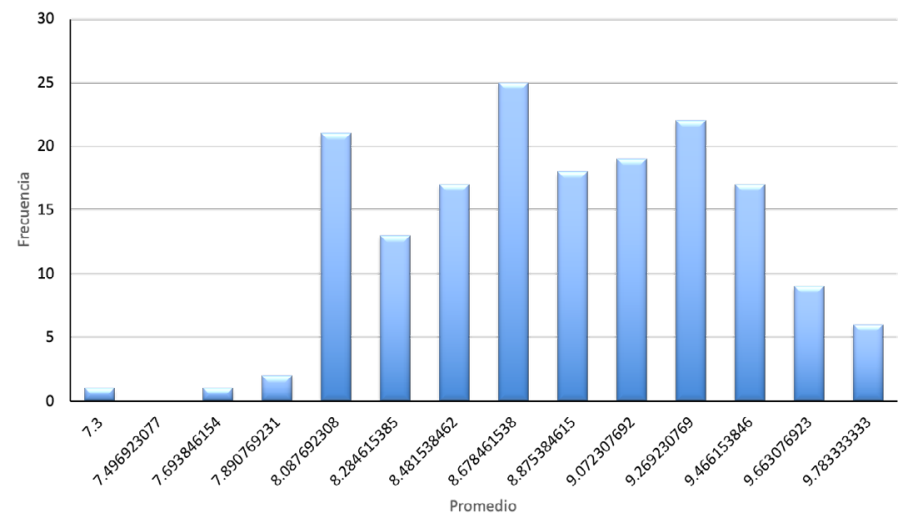

Figura 2.

Histograma de frecuencias del promedio escolar de los participantes.

Si bien podemos considerar una media relativa al promedio de calificaciones de 8.7 como buena, en términos del desempeño de los estudiantes convendría anali- zar si ese promedio refleja el aprendizaje del alumno y la incorporación de las competencias teóricas, metodológicas y aplicadas que requiere la profesión o, en su defecto, nos habla de criterios laxos en la evaluación de las distintas actividades académicas por parte de los tutores.

Respecto a la configuración familiar, en específico el estado civil, observamos que $40.1 \%$ son casados, $32.6 \%$ solteros, $13.4 \%$ viven en unión libre, $7.6 \%$ son divorciados, $4.1 \%$ separados y $2.3 \%$ viudos. En esta línea, al explorar el número de hijos se obtuvo que $35.5 \%$ de los participantes no tiene hijos, 30.2\% tiene dos hijos, $16.3 \%$ un hijo, $13.4 \%$ tres hijos, $3.5 \%$ mencionó tener cuatro hijos y $0.6 \%$ son los que tienen cinco o seis hijos. Las edades de los hijos son desde unos meses de nacidos hasta los 51 años (tabla 1).

Tabla 1.

Número de hijos que tienen los participantes.

\begin{tabular}{ccc|}
\hline $\begin{array}{c}\text { Número de } \\
\text { Hijos }\end{array}$ & Frecuencia & Porcentaje \\
\hline 0 & 61 & 35.5 \\
\hline 1 & 28 & 16.3 \\
\hline 2 & 52 & 30.2 \\
\hline 3 & 23 & 13.4 \\
\hline 4 & 6 & 3.5 \\
\hline 5 & 1 & 0.6 \\
\hline 6 & 1 & 0.6 \\
\hline
\end{tabular}

De acuerdo con lo anterior, la mayoría de los estudiantes tienen hijos y de distintas edades, lo cual indica que el ser madres/padres de familia es un aspecto central. No hay que olvidar que las modalidades de educación a distancia se adaptan más a las personas que tienen diversas actividades, ya sea porque están empleadas o porque tienen hijos.

Por otro lado, al analizar a qué se dedican los estudiantes detectamos que sólo $10.47 \%$ se dedica sólo a sus estudios, $71.51 \%$ estudia y trabaja, $15.7 \%$ estudia y efectúa actividades domésticas en su hogar, y $2.32 \%$ distribuye su tiempo entre estudios, trabajo y actividades domésticas (figura 3).

Si la educación a distancia permite continuar estudiando a personas que trabajan, que son amas de casa o que tienen diversas actividades que comprometen su tiempo, también podemos observar que hay jóvenes estudiantes en esta modalidad que quizá no encontraron la oportunidad de inscribirse en sistema presencial, de modo que se acoplaron a estudiar en un programa a distancia. Este es un dato importante porque indica que 
los programas a distancia permiten a diversos tipos de personas continuar sus estudios.

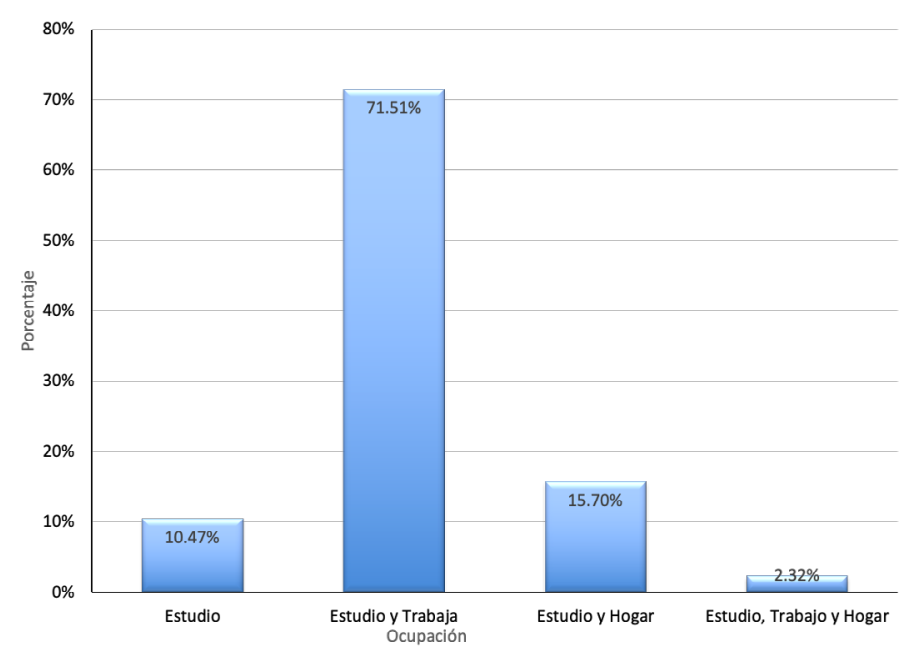

Figura 3.

Ocupación de los participantes.

Estos elementos del perfil socioeconómico del alumnado no deben considerarse como características generales de estudiantes a distancia. Hemos identificado estudios que muestran que hay estudiantes que son todavía jóvenes, pero optaron por universidades que ofrecían educación a distancia, o que tenían edades promedio de 30 años, pero no estaban casados ni tenían hijos (Chiecher, 2019). Aún más: hay universidades con modalidad a distancia cuyos estudiantes son en su mayoría jóvenes, sobre todo los que estudian el nivel licenciatura.

Al concentrarnos en el tiempo que invierten cada día los estudiantes que participaron en el estudio para estar en Facebook, nos indican que es poco más de una hora en promedio (64.58 minutos). Este dato presenta una desviación estándar de 68.32 minutos, siendo el número mínimo de horas que se dedican a la red social en cuestión un minuto y el máximo 540 minutos (nueve horas). La mayoría de los participantes dedica 60 minutos al día para consultar la red social $(25 \%)$, seguidos de 120 minutos $(16.3 \%)$ y 30 minutos $(15.7 \%)$.

El tiempo dedicado a los estudios cada día o a la semana es asunto importante porque dado que muchos estudiantes a distancia trabajan, son padres de familia y tienen compromisos con la crianza de los hijos, su tiempo para estudiar disminuye. Romero y Barberà (2013) indican que el estudiante a distancia tiene que negociar tiempos institucionales, laborales, familiares o de ocio para identificar los tiempos de calidad que le permitan cumplir con los objetivos de aprendizaje. No por dedicar tiempo a los estudios lograrán un buen desempe- ño académico, porque, por ejemplo, lo que se conoce como tiempo residual (estudiar en el transporte, en altas horas de la noche, después de concluir actividades familiares, etcétera), no ofrece los mismos resultados que cuando el estudiante se encuentra en mejores condiciones para desarrollar trabajo académico.

Respecto al uso que los estudiantes tienen de Facebook, se encontró que ingresan a esta red social de una a 30 ocasiones cada día. La mayoría ingresa diariamente entre una y cinco veces $(76.2 \%)$, predominando las siguientes frecuencias de ingreso diario: una vez $(23.3 \%)$, dos veces $(12.8 \%)$, tres veces $(14.5 \%)$, cuatro veces $(8.1 \%)$ y cinco veces $(12.8 \%)$. Estos datos indican que los estudiantes tienen una amplia actividad en Facebook, aunque una cuarta parte reporta tener baja actividad y sólo $4.7 \%$ de los participantes mencionó no usar Facebook. No se identificó asociación alguna entre el número de veces que usan Facebook diariamente y la edad de los participantes.

Cuando organizamos las respuestas proporcionadas al reactivo que exploró cómo fue que los estudiantes empezaron a usar Facebook, identificamos seis categorías en las que podemos agrupar sus respuestas.

- 1. Recomendación familiar. En esta categoría se integran los estudiantes que por recomendación de algún familiar (hermanos, pareja, sobrinos o hijos) decidieron abrir su cuenta en Facebook. A continuación presentamos algunas respuestas que ejemplifican este aspecto.

"Mi hermana menor me obligó para comunicarnos" (femenino, 37 años, unión libre).

"Por mi esposo" (femenino, 39 años, casada).

"Por recomendación de mi hermano" (femenino, 40 años, unión libre).

"Porque un sobrino me explicó su uso" (femenino, 44 años, separada).

"Por iniciativa de mi hija" (femenino, 47 años, casada).

De acuerdo con estos comentarios, empezar a usar Facebook fue en respuesta a las necesidades de comunicación que sus familiares tenían y para incluirlos en una actividad compartida. Incluso los familiares se ofrecieron a apoyar para el aprendizaje en el uso de la herramienta comunicativa en cuestión.

- 2. Recomendación de amigos. En esta categoría se incluyen las respuestas que refieren a la sugerencia abierta de algún amigo o grupo de amigos. A continuación presentamos varios ejemplos.

"Por recomendaciones de amigos" (masculino, 23 años, soltero).

"Porque unas amigas me lo recomendaron" (masculino, 25 años, soltero). 
"Una amiga me lo recomendó para estar en contacto todo el día" (femenino, 27 años, soltera).

"Por recomendación de amigos y para jugar" (femenino, 29 años, casada).

"Me llegó invitación de un amigo" (masculino, 36 años, soltero).

"Por un amigo fanático de computación que me enseñó un juego en Facebook" (femenino, 46 años, soltera).

En estos comentarios los estudiantes se refirieron al papel de las amistades para su inclusión en Facebook. Ya no sólo se trataba de estar en comunicación, sino también para darle un giro lúdico a la aplicación.

- 3. Recomendación escolar. En esta categoría observamos el inicio del uso de Facebook relacionado con la vida académica de los estudiantes. Se identifica la relación de estudios en línea (bachillerato o licenciatura) con la apertura y uso de la cuenta de Facebook, y nos Ilamó la atención que no hubo ningún caso masculino que hiciera referencia al uso de Facebook derivado de alguna recomendación o situación escolar.

"Porque en el curso propedéutico de la licenciatura me solicitaron una cuenta para una actividad y, después, en el primer semestre fue el medio de contacto con los compañeros de un equipo" (femenino, 29 años, soltera).

"Por la escuela preparatoria" (femenino, 31 años, casada).

"Cuando ingresé me comentaron los mismos compañeros que abriera una cuenta para mantener el contacto y compartir información" (femenino, 42 años, casada).

"Hice mi bachillerato en línea y era un requisito" (femenino, 45 años, unión libre).

Fue interesante encontrar que varios estudiantes tuvieron que ingresar a Facebook como un requisito para participar en actividades escolares. Ya fuera en el nivel de preparatoria o en el universitario, a los estudiantes se les demandó que se dieran de alta en Facebook como herramienta para el intercambio de información, permanecer en contacto con los demás, y quizá para recibir documentos y datos relativos a las materias. Así, Facebook no fue sólo una aplicación para comunicación social y ocio, sino también para actividades formales escolares.

- 4. Recomendación laboral. En general las respuestas en esta categoría se refieren a las relaciones en el entorno laboral o sus demandas, ya sea por recomendación de los compañeros de trabajo, por un requerimiento de la organización en diversas cuestiones, o para atender las actividades asignadas.
"Por compañeros en el trabajo" (femenino, 37 años, soltera).

"Por requerimiento de mi trabajo" (masculino, 41 años, casado).

"Por promoción en mi trabajo" (masculino, 43 años, casado).

"Por la actividad laboral" (femenino, 46 años, unión libre).

"A raíz de mis actividades laborales, como una forma de estar conectada con clientes" (femenino, 57 años, divorciada).

También fue interesante advertir que a partir del contexto laboral en que participan, los estudiantes tuvieron que aprender a usar Facebook para distintas tareas. Este es un dato que no hemos visto reportado en otra investigación y llama la atención porque el estudiante a distancia tiene que combinar aspectos identitarios como empleados, padres de familia y adultos; y una aplicación como Facebook es usada para cubrir aspectos de comunicación, ocio y tareas estudiantiles o laborales.

- 5. Imitación. En el caso de las respuestas que dan cuenta de esta categoría se identifica que los estudiantes observaron o tuvieron conocimiento de que alguien más usaba la red social y eso los llevó a abrir su cuenta. La mayoría de las respuestas contienen la palabra "moda" o indican que observaban que alguien más tenía una cuenta o hablaba de la red social. A diferencia de la categoría denominada "Recomendación de amigos", en este caso no se alude a una sugerencia verbal directa, sino que la decisión se toma a partir de observar o escuchar comentarios acerca de la red social.

"Cuando estuve en la secundaria se puso de moda e hice mi perfil" (masculino, 23 años, soltero).

"Cuando mis compañeros comentaban que lo usaban me llamó la atención" (femenino, 32 años, casada).

"Por moda; todos tenían Facebook; decidí abrir una cuenta" (femenino, 34 años, casada).

"Por imitar a otras personas, porque todos tienen Facebook" (masculino, 40 años, casado).

De acuerdo con estos comentarios, los estudiantes se reconocieron como personas insertas en relaciones sociales y como aprendices que se apropiaban de las actividades que veían en los demás. Se ubicaron también en una época en que estaba "de moda" el empezar a relacionarse por medio de redes sociales en línea.

- 6. A partir del uso asiduo de TIC. En este caso no se observa influencia social alguna asociada a la decisión de abrir una cuenta en Facebook; una palabra que con frecuencia se encuentra en las respuestas es "curiosidad", como se observa en los siguientes ejemplos. 
"Desde que empezaron a salir las redes sociales como Hi5, Metroflog y Myspace, fui cambiando de red social conforme tenían mayor demanda, hasta que apareció Facebook y no la he dejado de usar porque es la mejor red social y con mayor demanda" (femenino, 26 años, soltera).

"Por curiosidad" (femenino, 27 años, soltera).

"Ya había manejado otras redes sociales como Badoo, Skype, Window live" (femenino, 31 años, soltera).

Es interesante que varios de los estudiantes menores de 36 años dijeran que antes habían estado practicando su participación en redes en línea, o que sintieron curiosidad por conocer cómo funcionaba Facebook. No hay que olvidar que se trata de una generación de personas que nacieron en una época en que se gestaba un gran auge de las TIC, de modo que estaban a la mano para ser aprovechadas.

De acuerdo con Paquienséguy y Pérez (2010), en estos estudiantes se dio un proceso de apropiación de una tecnología, de modo que la incorporaron en las prácticas sociales cotidianas y así tuvieron que suceder procesos de aprendizaje, conocimiento y transmisión acerca de los usos y funciones de Facebook, y la puesta en marcha de diversas habilidades de los estudiantes.

Después de analizar cómo fue que empezaron a utilizar Facebook, dirigimos nuestra atención a identificar en cuáles campos de actividad los estudiantes comentaron que usaban más esta herramienta, y encontramos las siguientes combinaciones: A) Académicas, B) Ocio, C) Laborales, D) Académicas-Ocio, E) Ocio-Laborales-Académicas, F) Laborales y Ocio, y los que reportaron no usar Facebook. El porcentaje mayor se observa en el uso de Facebook para actividades de ocio $(45.7 \%)$, seguida de actividades académicas y de ocio (30.5\%). Sólo 8.5\% informó usarlo para actividades académicas (figura 4).

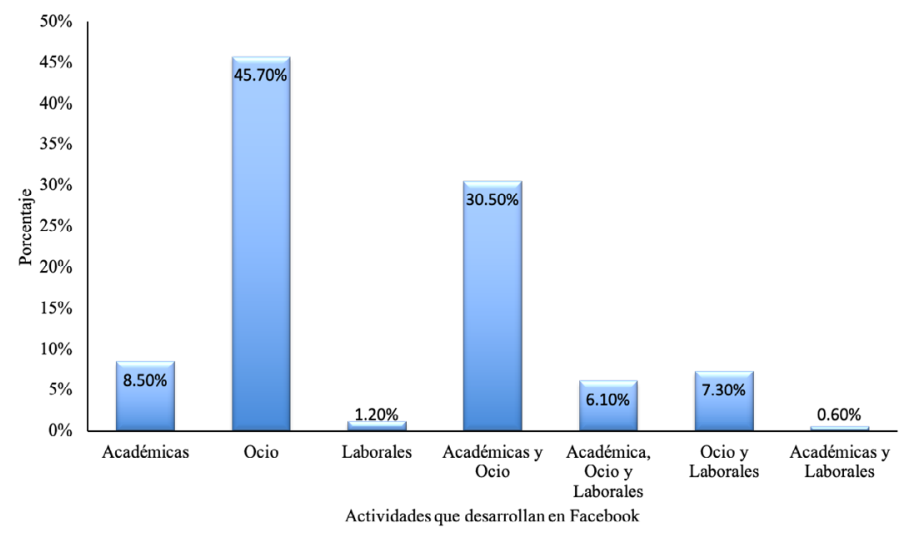

Figura 4.

Actividades que desarrollan en facebook.
Las actividades en que se usa Facebook coinciden con lo que reporta la literatura; Marchan y Juárez (2011) enlistan las actividades efectuadas en Facebook por sus usuarios: comunicarse con familiares o amigos, seguir y opinar acerca de cultura, entretenimiento y deportes, seguir y opinar de las últimas noticias, conocer o relacionarse con personas desconocidas, seguir ofertas comerciales de productos en general, ubicar geográficamente productos o servicios, desarrollar actividades empresariales, vender productos o servicios y buscar empleo. Estas actividades se enmarcan en las categorías que identificamos en las respuestas proporcionadas por los participantes en nuestro instrumento.

Los datos obtenidos concuerdan también con lo descrito por Cortés (2015), quien sostiene que los usuarios de Facebook usan esta red para comunicarse con amigos o como actividad secundaria mientras efectúan actividades escolares. Esto da sentido a la segunda categoría de uso de Facebook, que fue la de actividades académicas y de ocio, reportada por $29 \%$ de los estudiantes que contestaron nuestro instrumento.

A continuación exponemos algunos comentarios que hicieron los estudiantes de nuestra muestra referente a las tres grandes áreas en que dijeron utilizar Facebook con mayor frecuencia.

- 1. Actividades académicas. Se consideran las actividades relacionadas con el entorno escolar, como establecer comunicación con compañeros o profesores (tutores), buscar información relacionada con las asignaturas (módulos), procesos académico-administrativos, mensajes de las autoridades académicas (coordinación) e información relativa a actividades extracurriculares (cursos, congresos, coloquios, etcétera). En seguida presentamos varios ejemplos de las actividades reportadas por los estudiantes de esta categoría.

"Estar pendiente de eventos de Psicología, página de Psicología de la sede Tlaxcala" (femenino, 28 años, soltera).

"Para mantenerme en contacto con compañeros de equipo de los diferentes módulos y para estar pendiente de las noticias importantes relacionadas con mi carrera en los grupos o el portal de becarios" (femenino, 28 años, unión libre).

"Apoyo a compañeros estudiantes..." (femenino, 28 años, unión libre).

"Para saber cuándo hay cursos, para preguntar acerca de algún material para una actividad escolar" (femenino, 34 años, soltera).

"Apoyo académico, recursos en línea como libros y artículos científicos" (femenino, 34 años, unión libre). 
"Obtención de información acerca de temas de interés como las NEE" (femenino, 32 años, unión libre).

"Contacto con estudiantes, tutores, amigos, grupo de estudiantes, grupos de psicología" (femenino, 48 años, casada).

Los comentarios de los estudiantes muestran la importancia que dan al uso de Facebook para el apoyo de actividades académicas. Ellos han aprendido estrategias para usar esta herramienta de diversas maneras y así permanecer informados, en comunicación, en actividades de apoyo con los demás compañeros, sin perder el contacto con la institución escolar y con las novedades de la disciplina que estudian.

- 2. Actividades de ocio. Se incluyen las actividades relacionadas con la distracción, esparcimiento, la participación social o cívica, como leer noticias, distraerse, compartir literatura y comunicarse con familiares o amigos, entre otras. Los siguientes ejemplos ilustran las actividades indicadas por los estudiantes respecto a esta categoría.

"Recreación, actualización de noticias, comunicación y ampliación de conocimientos" (femenino, 29 años, soltera).

"Compartir libros, poesía, frases de la literatura que voy explorando o cursos que estoy tomando" (femenino, 29 años, casada).

"Para checar publicaciones de amigos, chatear con un amigo, verificar estados de personas, nuevas fotos, memes" (masculino, 30 años, soltero).

"Para interactuar con familiares y amigos y estar al tanto de noticias en los grupos en que estoy agregada" (femenino, 26 años, casada).

"Compartir noticias de periódicos o páginas de noticias" (masculino, 29 años, soltero).

"Interacción con amigos locales y a distancia..." (femenino, 29 años, casada).

"Socializar, grupos de Psicología, grupos de lectura, compras, grupos de interés personal" (femenino, 34 años, casada).

"Distracción, ver videos y noticias, mantenerme en comunicación con amigos y familiares" (femenino, 35 años, soltera).

"Para distraerme, para publicar aspectos de mi vida como fotos o historias, para estar en contacto con mi familia y amigos, y me sirve como modo de acceso en apps y programas" (femenino, 26 años, soltera).

"Activismo digital feminista..." (femenino, 29 años, casada).

"Para promover una asociación civil" (femenino, 55 años, casada).
"Activista político por un México mejor" (masculino, 60 años, casado).

La diversidad de temáticas y usos que indicaron tener los estudiantes es notable. Permite ampliar la noción de "ocio" porque se refiere no sólo a pasar el tiempo, socializar y divertirse, sino que incluye actividades de arte, información política, activismo y hasta posibles cursos que complementan la formación que buscan y que se asocian con otros aspectos de sus vidas.

- 3. Actividades laborales. Se incluyen actividades comerciales (ventas), publicidad (promoción de ventas), de reclutamiento y relacionadas con la vida laboral del estudiante en cuestión, como puede ser la administración de las redes sociales de la empresa donde labora y búsqueda de trabajo. Así, mostramos algunos ejemplos de los argumentos que dieron los estudiantes.

"Promoción de ventas de mi tienda en línea..." (masculino, 29 años, soltero).

"Fines comerciales (redes sociales de mi empresa)" (femenino, 29 años, casada).

"Reclutamiento..." (femenino, 30 años, soltera).

"Búsqueda de información laboral" (femenino, 30 años, casada).

"Ver publicaciones de ventas" (masculino, 40 años, casado).

"Publicaciones en el ámbito laboral" (femenino, 45 años, casada).

Facebook es una plataforma amigable para buscar y difundir distintos tipos de información, en particular lo relativo a asuntos laborales que competen a los estudiantes de nuestra muestra dado que, en su mayoría, son personas que necesitan empleo para continuar estudiando.

Por otro lado, la encuesta aplicada a los estudiantes también consideró la percepción que tenían respecto de qué tan competentes se sentían al utilizar Facebook en las distintas actividades. Aranda, Rubio, Di Giusto y Dumitrache (2019) analizaron mediante escalas qué tan competentes para el uso de TIC en general eran estudiantes universitarios. El cuestionario consideraba dominios básico, medio y avanzado, según los cuales los estudiantes reportaban si sabían tareas sencillas como crear un documento en Word, navegar por internet, hasta mucho más complejas como diseñar páginas web o usar software en trabajo colaborativo. EEn nuestra encuesta en línea no les indicamos a los estudiantes las características de las competencias de acuerdo con nivel de dominio, pero fue interesante que ellos sí se ubicaron en alguno.

Identificamos que $37 \%$ de los estudiantes se considera medianamente competente en el uso de Facebook; seguido de $23.78 \%$ que se asume como poco competente; 18.9 y $11.59 \%$ se perciben como muy compe- 
tentes y competentes, respectivamente, y sólo $8.53 \%$ se asume como no competente en el uso de la red social y sus herramientas (figura 5).

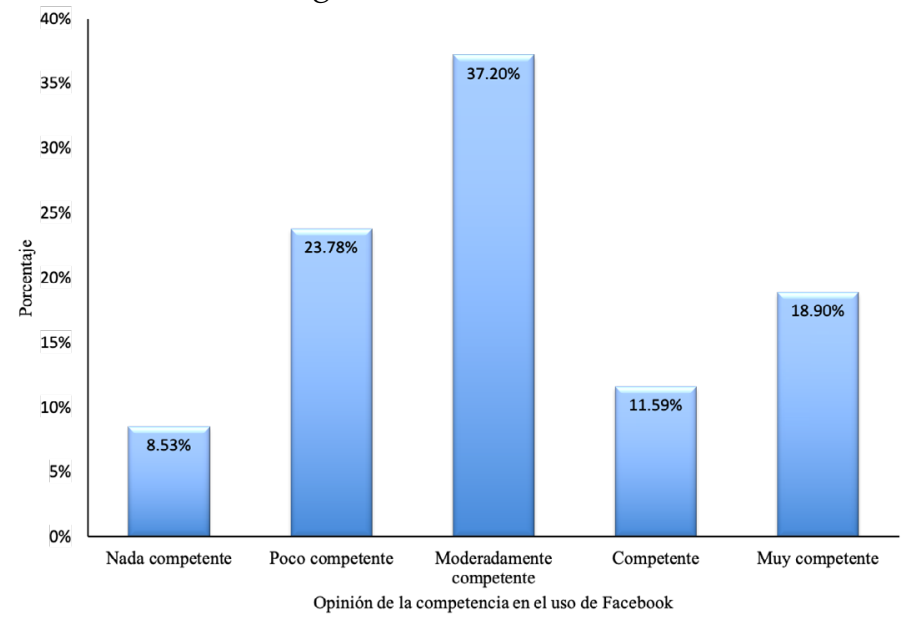

Figura 5.

Competencia en Facebook.

Además de cuestionar a los estudiantes acerca de su percepción respecto al dominio de Facebook se recopilaron los argumentos que fundamentaban su opinión. Presentamos por cada categoría algunos ejemplos de los argumentos que proporcionaron.

- Muy competente. Se refieren al tiempo que ha transcurrido desde que empezaron a usar la red social, a la cantidad de herramientas de la red social que usan, a la diversidad de archivos que comparten y al dominio de la configuración personalizada que ofrece.

"Porque ya tengo mucho tiempo usándolo" (femenino, 23 años, soltera).

"Conozco todas las herramientas" (masculino, 23 años, soltero).

"Porque reviso que las publicaciones que leo y comparto son de fuentes confiables o páginas oficiales, y también trato de alejarme de perfiles que generen spam o información poco confiable" (masculino, 23 años, soltero).

"Porque puedo buscar datos, información, conversar, compartir opiniones, usar las herramientas que proporciona para mi uso personal" (femenino, 24 años, soltera).

"Porque puedo limitar su uso, tengo la decisión del tiempo a utilizarlo, y no lo uso estando con amigos o familia, conozco la manera de aplicar las restricciones y candados de privacidad con mucha facilidad" (masculino, 25 años, soltero).

"Envío archivos, subo fotos, descargo materiales con facilidad, consigo direcciones o información que re- quiero de manera muy rápida" (femenino, 47 años, casada).

"Aprovecho los recursos que tiene para cubrir diferentes necesidades de comunicación y diversión" (masculino, 45 años, casado).

"Entiendo todas las configuraciones que ofrece" (femenino, 42 años, divorciada).

Como podemos observar, independientemente del género, edad y estado civil los argumentos referentes al dominio que los estudiantes reportan de Facebook y sus herramientas son similares. Aunque no les indicamos en la encuesta en qué consistiría un domino alto de la herramienta, los comentarios que ofrecieron concuerdan con lo indicado por Aranda, Rubio, Di Giusto y Dumitrache (2019) respecto a que los estudiantes se reconocieron como habilidosos en el uso de utilidades que ofrece Facebook.

- Competente. Se observa que los argumentos giran en torno a un menor uso de sus funciones y porque dicen tener un conocimiento superficial o básico de sus herramientas. Algunos indican usarlo como una herramienta de interacción general o de ocio, aunque puedan no publicar; otros mencionan que la usan para atender sus actividades académicas.

"Puedo utilizarlo sin problema para obtener información que necesito, pero no conozco a profundidad todas las funciones que tiene" (femenino, 26 años, soltera).

"Me puedo movilizar de manera eficiente y rápida en el Facebook, y puedo comentar estados, publicar, compartir equis cosas y nada más" (masculino, 30 años, soltero).

"Porque si deseo buscar un grupo para aprender idiomas, buscar personas, libros, películas, etcétera, puedo hacerlo bien" (femenino, 34 años, soltera).

"Sé utilizarlo muy bien, pero tampoco es algo tan importante para mí; casi no publico" (femenino, 34 años, casada).

"Exploro grupos y adquiero información de manera fácil y rápida" (femenino, 34 años, unión libre).

"Porque puedo usar lo básico, lo necesario" (masculino, 42 años, casado).

En esta categoría también se observa que, independientemente del género, la edad y el estado civil de los estudiantes, los argumentos que fundamentan su percepción del dominio de Facebook son muy semejantes, enfocándose al tiempo de uso y el número de herramientas utilizadas y su dominio. Los estudiantes consideraron que tenían un uso competente porque reconocían no utilizar funciones más complejas que tiene Facebook, sin que hicieran alusión a las mismas. 
- Moderadamente competente. En esta categoría los estudiantes expresaron argumentos relacionados sobre todo con el uso recreativo de las herramientas que tiene Facebook, y lo que podríamos denominar un uso pasivo al sólo revisar las publicaciones que hacen otros; de este modo, reconocen el poco conocimiento de algunas de las opciones que proporciona, como la configuración de seguridad.

"Porque no lo uso durante mucho tiempo, y cuando lo hago sólo es para revisar publicaciones, como para distraerme un poco" (femenino, 22 años, soltera).

"Me siento regular competente porque sé de más personas que hacen muchas más cosas que yo en la App, como jugar, subir historias diarias, estar en grupos privados para conocer personas, detectar personas falsas, la moda en Facebook en videos o memes; hay muchas cosas que se pueden hacer en la página; sin embargo, no hago uso de todo" (femenino, 26 años, soltera).

"Porque muchas de las cosas que ofrece la aplicación las desconozco; hasta el momento en que veo que alguien las usa, me pregunto: ¿cómo es que se hace eso o aquello?" (femenino, 28 años, unión libre).

"Lo uso para mensajes y compartir fotos, pero no sé otras funciones como bloquear personas, borrar comentarios y muchas otras" (masculino, 47 años, casado).

"Lo dedico a la gestión de páginas y no a la interacción en un perfil privado" (femenino, 28 años, soltera).

"Porque sólo lo uso como consulta y diversión; no lo he explotado al máximo" (masculino, 47 años, casado).

$\mathrm{Al}$ igual que en las categorías anteriores no se observan diferencias en los argumentos que proporcionan los estudiantes que se relacionen con su edad, sexo o estado civil. Lo interesante es que estos estudiantes han identificado en otras personas un uso más complejo de Facebook, pero no han intentado avanzar en dicha competencia. Incluso hablan de otras funciones o tienen idea que puede haber muchas más que las que usan, pero han optado sólo por un uso básico.

- Poco competente. Los argumentos de los estudiantes que se consideran poco competentes se refieren a un uso escaso de la aplicación que involucra a pocas o sólo a una de las herramientas que ofrece, como la posibilidad de comunicarse con los contactos. En algunos casos se indica que la herramienta tiene un buen número de opciones que son desconocidas para ellos. "Porque sólo lo utilizo para información general; no atiendo a todas sus utilidades" (masculino, 23 años, soltero).

"Sólo lo ocupo para leer noticias e información relevante" (femenino, 23 años, unión libre).
"Como se va actualizando Facebook, a veces suele ser difícil conocer las novedades que se han hecho" (femenino, 23 años, soltera).

"En realidad no lo uso para publicidad o crear grupos y esas cosas más avanzadas" (femenino, 26 años, casada).

"Sé usar la plataforma de modo básico y esencial" (femenino, 27 años, soltera).

"Sólo lo utilizo para información general; no le pongo atención a todas sus utilidades" (masculino, 23 años, soltero).

"Casi no uso la aplicación" (femenino, 30 años, casada).

"Lo utilizo sólo para lo básico, que es comunicarme con compañeros, y ya que hoy el WhatsApp es el medio de comunicación más rápido, casi no lo utilizo" (femenino, 28 años, unión libre).

"Porque son muchas las herramientas y no las manejo" (masculino, 30 años, casado).

En esta categoría observamos otra vez contenidos homogéneos en los argumentos que proporcionan los estudiantes que se consideran competentes en el uso de Facebook, no habiendo diferencias de género, edad o estado civil. Aún más, estos estudiantes dicen ser poco competentes porque usan Facebook para actividades sencillas, sobre todo las de comunicación, a pesar de lo cual, e igual que el grupo previo, sí tienen conocimiento de que pueden haber otras funciones que ellos no conocen.

- Nada competente. En este caso los estudiantes aluden al escaso o nulo uso con fines educativos, a la ausencia de actividad (hacer publicaciones o compartir información), así como al escaso ingreso a la red social.

"No utilizo Facebook con fines educativos ni en el trabajo; sólo de ocio" (femenino, 28 años, soltera).

"No me gusta y no me interesa mucho; prefiero Twitter" (masculino, 36 años, casado).

"No publico ni comparto" (femenino, 37 años, casada).

"Hay muchas funciones que desconozco, y no estoy interesada en aprenderlas" (femenino, 39 años, casada).

"Casi no accedo a él; considero que no lo sé utilizar" (femenino, 43 años, casada).

"No conozco la aplicación y confundo los botones; muchas veces no sé cómo compartir imágenes" (femenino, 45 años, casada).

"No acostumbro usar Facebook" (masculino, 65 años, divorciado).

"Desconozco la herramienta; el uso es superficial" (femenino, 63 años, soltera). 
En ninguna de las categorías se observa alguna diferencia asociada al sexo, edad o estado civil de los estudiantes. Lo que sí se advierte fue que en este grupo que se ubicó como "Nada competente" no sólo dijeron desconocer la diversidad de funciones que tiene Facebook, sino que expresaron su desinterés por el mismo. Suponemos que para su desempeño como estudiantes a distancia sí han tenido que desarrollar competencias para el uso de las plataformas en las cuales tienen que participar (aulas virtuales, correo electrónico, servicios de mensajería como WhatsApp, Skype o Hangouts y uso de la nube, entre otros), pero a Facebook lo hacen de lado.

\section{Discusión}

La encuesta online que aplicamos a los estudiantes universitarios a distancia fue un instrumento accesible, un ejemplo de cómo la tecnología en la actualidad facilita la realización de actividades académicas, en este caso, la obtención de información respecto de quiénes son los estudiantes que investigamos. Al estar en contacto con las TIC los estudiantes a distancia en general tuvieron acceso a la invitación para participar en la encuesta que les mandamos y 172 de la muestra total optaron por responder. Esa cantidad está a un punto para acercarse a ser una muestra representativa del total de alumnos a distancia que cursan los últimos semestres de la carrera y nos basamos en ella para construir un perfil del estudiantado. Como estudio exploratorio, la encuesta en línea nos permitió conocer aspectos generales del perfil socioeconómico de los estudiantes a distancia, a la vez que identificar las percepciones que los mismos tenían sobre el uso y dominio de Facebook en distintas áreas de sus vidas.

Encontramos que se trata de alumnos universitarios que radican sobre todo en la Zona Metropolitana. Si bien se esperaría que un mayor número de estudiantes potenciales de los estados de la República tuvieran acceso a la educación a distancia, comprobamos que la misma tiene un impacto importante en residentes de la Zona Metropolitana, adultos jóvenes, adultos, y menos en adultos mayores y jóvenes. La educación a distancia también es una opción para jóvenes que se dedican sólo a estudiar, pero que no lograron inscribirse en modalidad presencial o que optaron por ese modelo por diversas razones. Lo anterior coincide con Contreras y Méndez (2015), quienes indican que la oferta educativa a distancia es una opción de formación profesional para habitantes de toda la República que no tienen la posibilidad de acceder a las opciones presenciales. Sin embargo, es interesante el predominio de los estudiantes del área metropolitana de la Ciudad de México, pues aunque el objetivo de la oferta educativa a distancia dentro de la UNAM es llevar la educación superior a cada rincón del país que tenga conexión a la red (Díaz y Canales, 2011), a la fecha no se ha cumplido y podemos afirmar que esto se debe a la conectividad limitada que hay en nuestro país.

Observamos que el estudiantado que participó en esta investigación se caracterizó por tener condiciones familiares diversas, como ser solteros, estar casados, ser viudos o encontrarse en unión libre; la mayoría con hijos y familia que sostener. En este aspecto validamos que la educación a distancia permite a los estudiantes adultos continuar sus estudios universitarios a la par que tienen otras ocupaciones de vida. Silva (2016) afirma que los estudiantes de educación a distancia se caracterizan por combinar los estudios con otras responsabilidades de la vida adulta, como la atención a una familia o cumplir con las responsabilidades de un trabajo. En esta investigación tuvimos la posibilidad de confirmarlo porque los participantes distribuyen su tiempo en actividades escolares, del hogar y laborales, siendo la mayoría de la muestra quienes combinan estudio y trabajo. Es lamentable que la mayor parte de su tiempo se enfoca a lo laboral, y eso puede tener un efecto considerable en su rendimiento y formación profesional.

Ya se ha visto en las investigaciones referente al estudiantado a distancia que si bien es cierto que los estudios en línea tienen la característica de ser accesibles, flexibles, que se ajustan a tiempos y ritmos de trabajo del estudiante, ubicuos porque se puede entrar a las plataformas educativas desde diferentes lugares, y que pueden cubrir una amplia gama de participantes acorde a género, edad, lugar de residencia, etcétera (García, 2017), también es cierto que dadas las ocupaciones del estudiantado dedican tiempo residual a las actividades académicas, lo que puede ir en detrimento de la calidad en su formación profesional (Romero y Barberà, 2013). Empero, en la presente investigación encontramos que en el plano académico la mayoría de los estudiantes reportaron tener un buen promedio de calificación (8.7). Previamente nos preguntamos si es que las estrategias de evaluación y asignación de calificaciones por parte de los docentes buscan ajustarse a las posibilidades de trabajo y participación académica del estudiantado, de ahí que en general reporten un promedio alto. Esta es una línea a analizar con cuidado en futuras investigaciones con estudiantes a distancia en la carrera que exploramos. No es un tema nuevo la cuestión de la evaluación del estudiante a distancia, e incluso se discute la diferencia entre evaluación formativa, evaluación sumativa y diseño de tareas, entre otras, y se elaboran propuestas 
específicas para captar la especificidad de las evaluaciones en educación a distancia (Dorrego, 2016).

Ahora bien, en nuestra muestra encontramos que algunos estudiantes tuvieron procesos de apropiación diversos para el uso de Facebook. Estos estudiantes pertenecen a una generación de jóvenes y adultos para los cuales se les demanda el uso de las TIC, ya sea mediante peticiones que les hicieron familiares, amistades o para asuntos laborales. Habría que acotar que son estudiantes citadinos, universitarios, empleados, y que por ello la demanda para el uso de TIC, y en particular Facebook, toma sentido. Según dijeron, ellos también vieron cómo sus conocidos empezaban a compenetrarse en el mundo de las TIC, y para no quedar aislados o para sostener vínculos de comunicación también se integraron. El uso de las TIC permite a la gente ingresar en comunidades virtuales que refuerzan y/o complementan las que tienen de modo personal.

Hoy la investigación ha encontrado que los jóvenes tienen un amplio uso de TIC y de Facebook, y se ha trascendido su uso social o de comunicación en tiempos libres para sostener estrategias de comunicación y aprendizaje académico (Abúndez et al., 2015; González y Delgado, 2015). En relación con nuestro objetivo, que fue conocer la percepción de dominio y los usos de Facebook, en nuestra muestra los estudiantes en general reportaron utilizar Facebook diariamente, entrando desde una vez o hasta cinco veces al día. Es necesario destacar que muy pocos $(8.1 \%)$ reportaron entrar a Facebook sólo con fines académicos, y que la gran mayoría reportó usar esta herramienta para actividades de ocio, académicas y laborales. Esto denota que Facebook es utilizada para cubrir distintas demandas de los estudiantes, ya sea de diversión, relativas a su formación profesional y laborales que corresponden a su condición como empleados. Así, Facebook es una herramienta para usos diversos, y los estudiantes en línea la utilizan para cubrir distintas facetas de actividad online en sus vidas.

Además resultó interesante encontrar que reportaron usar Facebook en el ámbito académico, no sólo para estar en contacto con sus compañeros, sino para mantenerse informados acerca de eventos, programar sus cursos, identificar cursos en línea y rastrear temas de interés. Ya se ha dicho que Facebook es una de las plataformas más completas (Abúndez et al., 2015), y muchos de los estudiantes a distancia la usan de manera creativa. También usan Facebook para asuntos de ocio y laborales muy creativos: estar al pendiente de noticias y política, socializar en grupos específicos, promover una asociación civil, promover ventas de su tienda en línea y búsqueda de empleo. Esto indica la necesidad de diversificar lo que entendemos por actividades de ocio, porque se le ha entendido como chatear, intercambiar memes, publicar estados emocionales en el muro y enviar mensajes, todos estos aspectos relacionados con la comunicación social. En nuestros jóvenes y adultos estudiantes universitarios a distancia se observa un uso también diversificado con intereses específicos a su condición de profesionistas en formación y de empleados en búsqueda de mejores oportunidades.

Por último indagamos cuáles eran las percepciones que tenían respecto a qué tan competentes eran en el uso de Facebook, y la mayoría relativa se ubicó en moderadamente competente. Muy pocos se posicionaron en poco competentes, y un poco más de la cuarta parte dijo estar entre competente y muy competente. Llama la atención que se ubicaron en cada una de estas categorías porque se observaron y enlistaron las competencias que creían tener, o las que conocían, pero pensaban que no habían desarrollado. Todos reconocieron que Facebook es una plataforma con una diversidad de opciones, y todos aludieron a lo poco o mucho que explotaban esta herramienta para sus actividades académicas.

Aranda et al. (2019) consideran que hoy es necesario que los estudiantes universitarios dominen las TIC porque permiten concretar una inteligencia colectiva, una gestión diferente de los procesos de enseñanza-aprendizaje, aumentan la fluidez y sencillez de la comunicación entre los actores de la educación y facilitan la coordinación del trabajo en equipos, entre otros. Sostenemos que los estudiantes a distancia pueden tener un mejor desempeño si utilizan de manera competente Facebook. Esta sería otra posible línea de indagación futura.

Para concluir, Facebook es una plataforma de enorme utilidad para el estudiante a distancia. Si bien no se le incluye de manera formal en los diseños instrumentales que se tienen en el Sistema de Educación a Distancia de la universidad en que desarrollamos la investigación, los estudiantes la usan de manera activa para apoyar sus actividades académicas. Estos estudiantes han tenido que aprender a ser competentes en el uso de Facebook gracias a las demandas que sus conocidos hacen para incorporarlos en este mundo virtual, y a la necesidad de complementar y enriquecer aspectos de su formación académica. Una línea más de indagación sería cómo combinan estos estudiantes su uso de Facebook con otras TIC para llevar a cabo el cúmulo de actividades académicas que tienen que resolver en sus tiempos residuales.

Facebook es una plataforma que permite a los estudiantes canalizar diversos intereses, de modo que en tiempo combinado pueden atender aspectos de ocio, académicos y laborales. Esto no se contempla en ninguna plataforma académica que se maneje en alguna 
universidad. Una última línea de indagación que proponemos es en qué medida los diseños universitarios para estudiantes a distancia pueden emular la riqueza y posibilidades de uso de Facebook para la orientación y formación del estudiante a distancia.

\section{Referencias}

Abúndez, E., Fernández, F., Meza, L., \& Alamo, M. (2015). Facebook como herramienta educativa en el proceso de enseñanza-aprendizaje en el nivel medio superior. Zona Próxima, 22, 116-127.

Adaime, I. (2015). El Proyecto Facebook y la creación de entornos colaborativos educativos. En A. Piscitelli, I. Adaime e I. Binder (eds.). El Proyecto Facebook y la Posuniversidad. Sistemas Operativos sociales y entornos abiertos de aprendizaje. Barcelona: Ariel.

Agila, P. M., Ramírez, M. M., García, V. A., \& Samaniego, F. J. (2017). Uso de la tableta digital en entornos universitarios de aprendizaje a distancia. Revista Iberoamericana de Educación a Distancia, 20(2), 255-271.

Amaya, D. L., \& Rincón, J. E. (2017). Evaluación de la autorregulación académica en estudiantes de pregrado de la Corporación Universitaria de Dios UNIMINUTO, en la modalidad virtual-distancia. Revista Academia y Virtualidad, 10(1), 68-78.

Aranda, G. L., Rubio, R. L., Di Giusto, V. C., \& Dumitrache, C. (2019). Evaluación en el uso de las TIC en estudiantes de la Universidad de Málaga. Diferencias de género. Innoeduca: International Journal of Technology and Educational Innovation, 5(1), 63-71.

Artavia, D. Y., \& Castro, G. A. (2019). Implementación de herramientas tecnológicas en la educación superior universitaria a distancia. Educación Superior, XVIII(28), 13-30.

Badillo, M. (2012). Propuesta de comunicación y educación ambiental a través de Facebook y el uso de narrativas digitales. Entramado, 8(1), 128-139.

Bachiller, O. (2013). El análisis del nivel de participación en las redes sociales en internet, una experiencia a partir de la etnografía virtual en la educación superior. Perspectivas Educativas, 6, 175-190.

Cheung, Ch., Chiu, P., \& Lee, M. (2011). Online social networks: Why do students use Facebook? Computer in Human Behavior, 27, 1337-1343.

Chiecher, C. A. (2019). Estudiantes en contextos de educación a distancia. Variables vinculadas con el logro académico. Revista Iberoamericana de Educación a Distancia, 22(2). Disponible en http://www.redalyc.org/articulo. oa?id=331460297011

Contreras, O., \& Méndez, G. (2015). El perfil de los estudiantes en educación a distancia en México. En J. Zubieta y C. Rama (eds.). La educación a distancia en México: Una nueva realidad universitaria, pp. 47-64. México: UNAM.

Cortés, R. (2015). Uso y consumo de redes sociales virtuales entre estudiantes universitarios. Un acercamiento a los hábitos de multitarea. Revista Iberoamericana de Producción Académica y Gestión Educativa. 2. Disponible en http://
www.pag.org.mx/index.php/PAG/article/view/258

Díaz, A., \& Canales, A. (2011). Aplicación de las tecnologías de la información y la comunicación en la educación superior: El caso del SUAyED-UNAM. Reencuentro, 62, 30-36.

Dorrego, E. (2016). Educación a distancia y evaluación del aprendizaje. Revista de Educación a Distancia, 50, Disponible en https://revistas.um.es/red/article/ view/271241.

Espuny, C., González, J., Lleixà, M., \& Gisbert, M. (2011). Actitudes y expectativas del uso educativo de las redes sociales en los alumnos universitarios. Revista de Universidad y Sociedad del Conocimiento, 8(1), 171-185.

Gallo, P., Mora, A., \& Rozo, J. (2013). Comunicación e interacción en las redes sociales: Usos en procesos de aprendizaje. Tesis de licenciatura, Escuela de Ciencias Sociales, Artes y Humanidades, Universidad Nacional Abierta y a Distancia. Colombia.

García, A. L. (2017). Educación a distancia y virtual: Calidad, disrupción, aprendizaje adaptativo y móvil. Revista Iberoamericana de Educación a Distancia, 20(20), 9-25.

Gómez, M., Roses, S., \& Farías, P. (2012). El uso académico de las redes sociales en universitarios. Comunicar. Disponible en https://www.revistacomunicar.com/pdf/preprint/38/14PRE-13426.pdf.

González, C. F. L., \& Saucedo, R. C. (2020). El trabajo en equipo mediado por Facebook: Una iniciativa de estudiantes universitarios. Revista Digital Internacional de Psicología y Ciencia Social, 6(2), Disponible en http://cuved.unam.mx/ revistas/index.php/rdpcs/article/view/201.

González, J., \& Delgado, E. (2015). El caso de Facebook. Acercamiento al uso de las redes sociales para la construcción de lazos afectivos en la era digital. Memorias del XXVII Encuentro Nacional de la Asociación Nacional de Investigadores de la Comunicación: Historias y apuntes sociales de la investigación de la comunicación en México, pp. 271-288.

González, J., Lleixà, M., \& Espuny, C. (2016). Las redes sociales y la educación superior: Las actitudes de los estudiantes universitarios hacia el uso educativo de las redes sociales, de nuevo a examen. Education in the Knowledge Society, $17(2), 21-38$.

Hernández, R., Fernández, C., \& Baptista, P. (2014). Metodología de la investigación. México: McGraw-Hill.

Herrera-Batista, M. (2009). Disponibilidad, uso y apropiación de las tecnologías por estudiantes universitarios en México: Perspectivas para una incorporación innovadora. Revista Iberoamericana de Educación, 48(6), 1-9.

Hubach, G. (2013). Proyecto de ex-alumnos: Las TIC en la comunicación Institucional. Argentina. Disponible en www.pent.org.ar/centro-de-recursos/proyecto-exalumnos-tics-comunicación-institucional.

Judge, T., \& Robbins, S. (2009). Comportamiento organizacional. México: Pearson.

Marchant, I., \& Juárez, R. (2011). Redes sociales en México y Latinoamérica. México: Tesseract, Pages.

Martínez, M., \& Raposo, M. (2006). Las TIC en manos de estudiantes universitarios. Revista Latinoamericana de Tecnología Educativa, 5(2), 165-176.

Paquienséguy, F., \& Pérez, F. C. (2010). El aprendizaje en línea: 
Una forma de atender las necesidades de poblaciones estudiantiles diversas. Revista Educación, Comunicación, Tecnología, 4(8). Disponible en https://revistas.upb.edu. co/index.php/revista_Q/article/view/7803

Romero, M., \& Barberà, E. (2013). Identificación de las dificultades de regulación del tiempo de los estudiantes universitarios en formación a distancia. Revista de Educación a Distancia, 38. Disponible en http://www. um.es/ead/red/38

Sánchez, F., \& Arroyo-Cañada, F. (2016). La percepción de satisfacción de la red social virtual. Un análisis comparativo. Esic Market Economics and Business Journal, 47(1), 145-158.
Silva, A. (2016). Trayectorias escolares y eficiencia terminal. Revista Digital Internacional de Psicología y Ciencia Social, 1, 55-95. Disponible en https://www.researchgate. net/publication/316448999_Trayectorias_escolares_y_ eficiencia_terminal

Vega. V. Z., Gómez, E. G., Gálvez, J. F., \& Rodríguez, H. E. (2017). Estrés, afrontamiento y emociones en estudiantes universitarios de sistema a distancia. Revista Electrónica de Psicología Iztacala, 20(2), Disponible en www.iztacala. unam.mx/carreras/psicologia/psiclin 


\section{Meta-Análisis del Artículo}

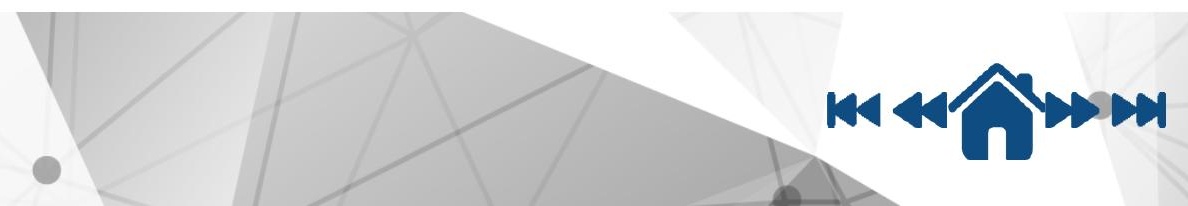


Revista Digital Internacional de Psicología y Ciencia Social $\mid$ Vol. 6 | SNúm. $2 \mid$ Julio-Diciembre 2020 | e-ISSN 2448-8119

\section{Dimensión Cuantitativa}

\section{Perfil de Evaluación entre pares}
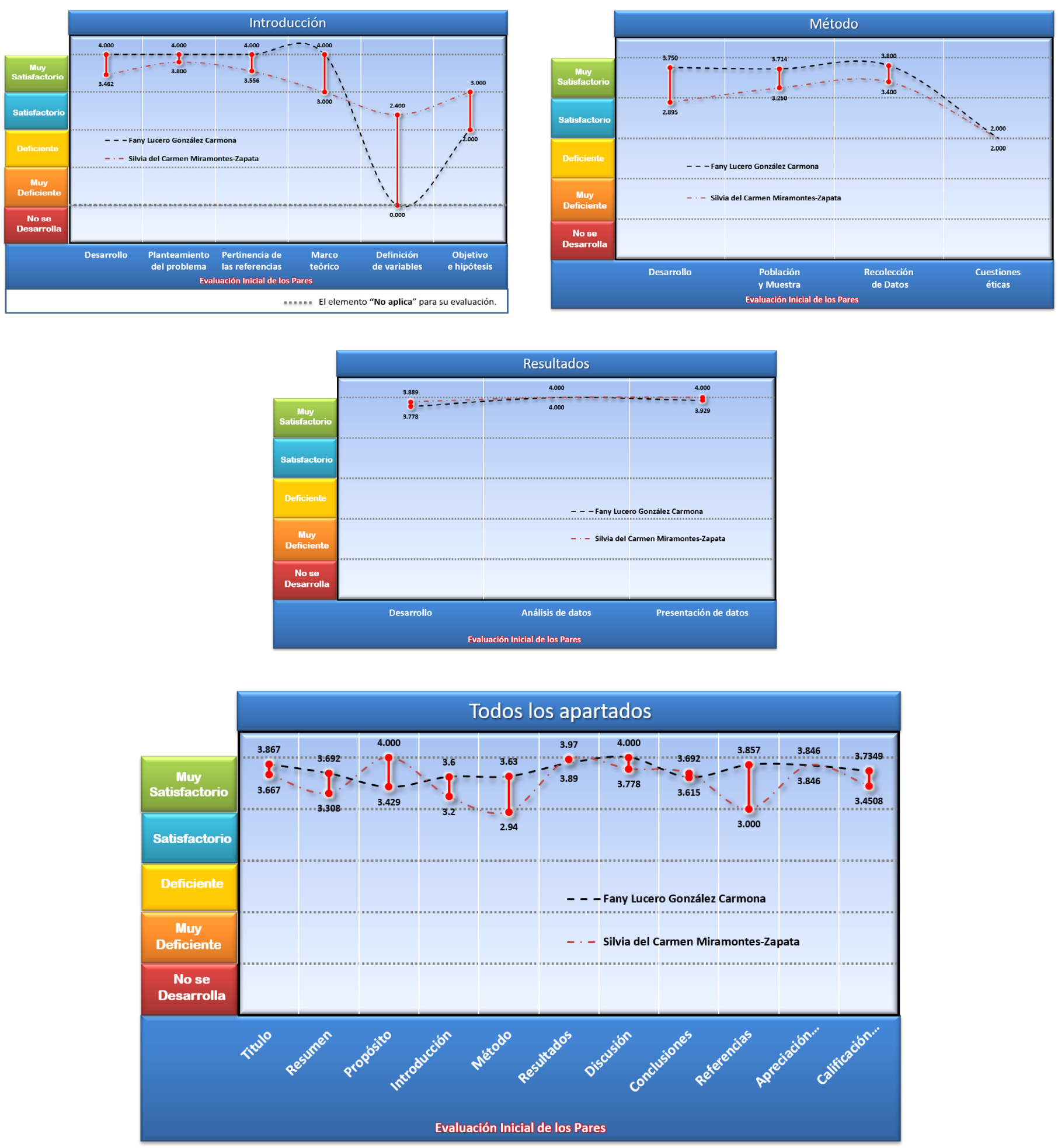


\section{Índice de Concordancia}

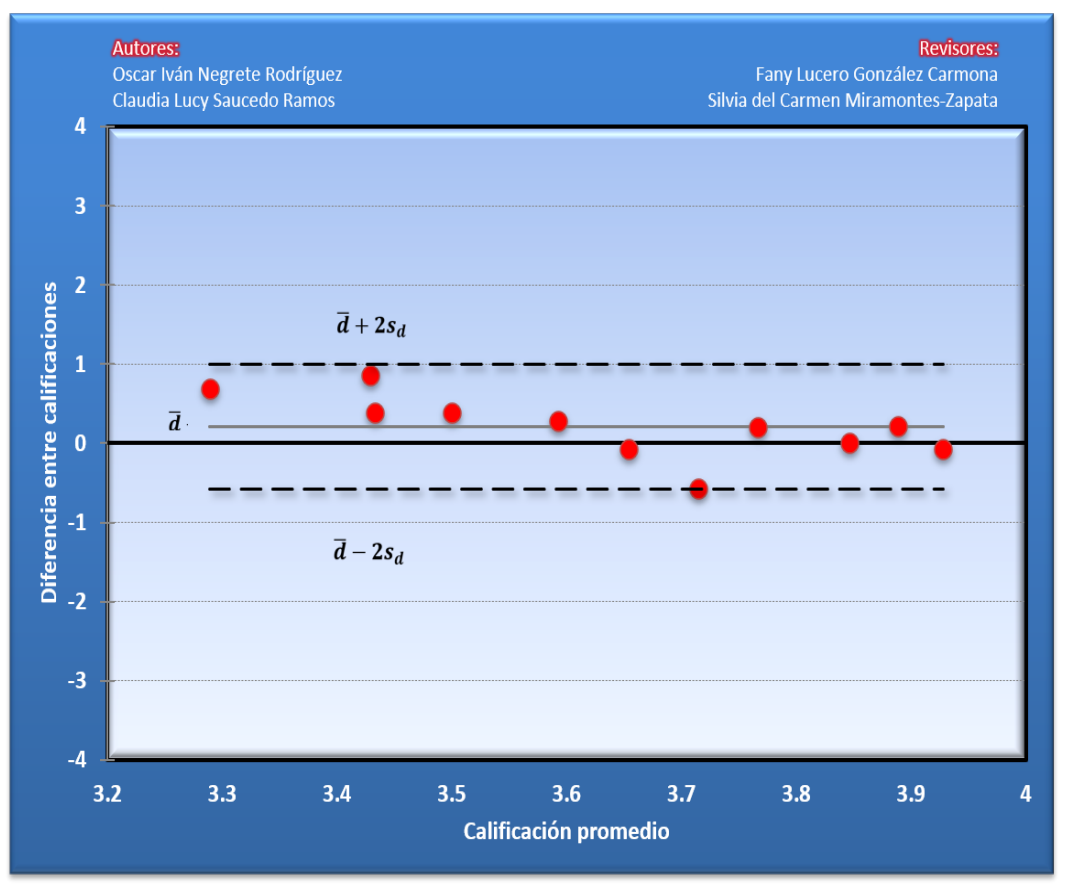

Índice de Acuerdo

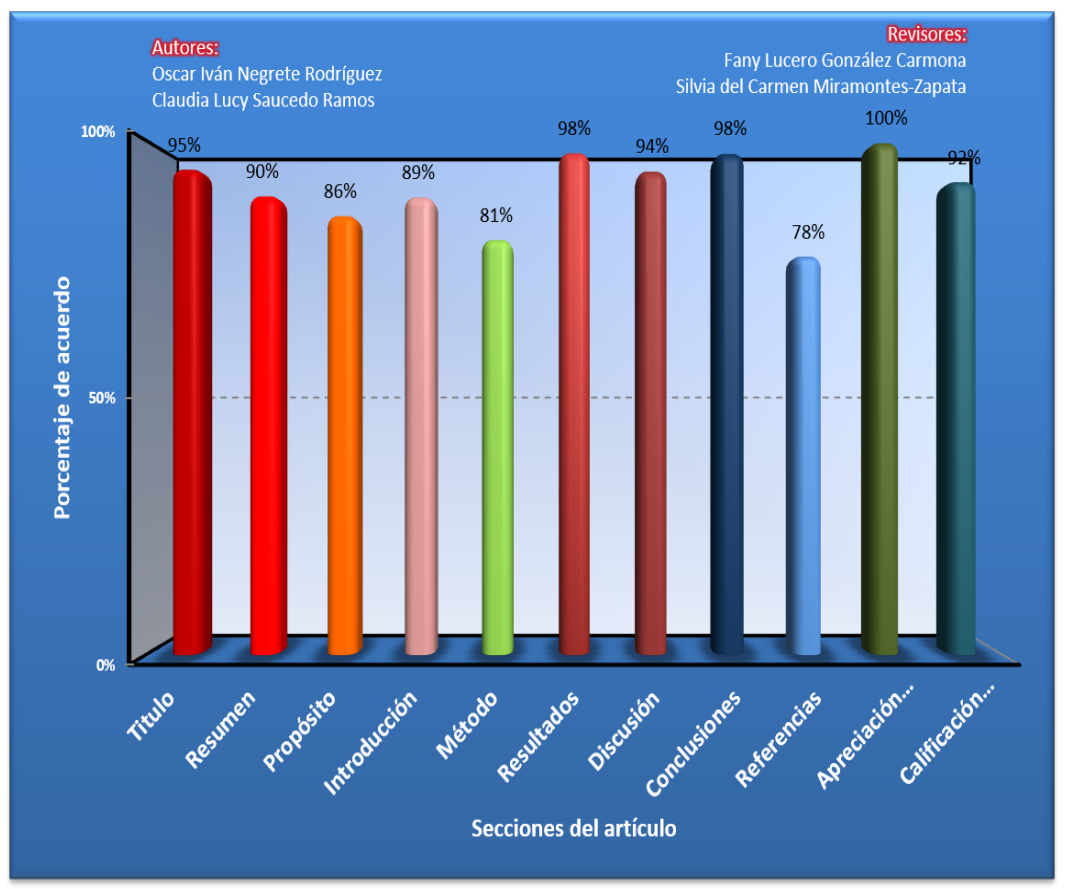




\begin{tabular}{|c|c|}
\hline Revisor 1 & Revisor 2 \\
\hline Fany Lucero González Carmona & Silvia del Carmen Miramontes-Zapata \\
\hline \multicolumn{2}{|c|}{ Título/Autoría } \\
\hline $\begin{array}{l}\text { Es un título es claro y explicativo; solo considero ne- } \\
\text { cesario reestructurar la redacción brevemente para re- } \\
\text { ducir el número de palabras ya que excede el máximo } \\
\text { establecido de } 15 .\end{array}$ & $\begin{array}{l}\text { Usos y percepción del dominio de Facebook en estudiantes } \\
\text { SUSTITUIR en POR de Psicología en su modalidad (agre- } \\
\text { gar A) Distancia. Eliminar: de una Universidad Pública del } \\
\text { titulo y dejarlo exclusivamente para la parte del método. }\end{array}$ \\
\hline \multicolumn{2}{|c|}{ Resumen } \\
\hline $\begin{array}{l}\text { El resumen es claro y cumple con los requerimientos esta- } \\
\text { blecidos. Solo considero necesario señalar la metodología } \\
\text { empleada, ya que únicamente plantearon el número de } \\
\text { participantes pero no las herramientas y tipo de metodo- } \\
\text { logía en la que se basaron. Tiene algunas breves cuestiones } \\
\text { de redacción que habría que mejorar y mínimas discre- } \\
\text { pancias entre el resumen en inglés y el resumen en espa- } \\
\text { ñol. Solo colocan tres palabras clave (una compuesta) es } \\
\text { necesario que cumplan con las cinco establecidas. }\end{array}$ & $\begin{array}{l}\text { No hay resultados numéricos en el resumen (por ejemplo, } \\
\text { señala que la mayoría pero no es específico). Tiene } 188 \text { pa- } \\
\text { labras no } 150 \text { que es el máximo. Sólo tiene } 3 \text { palabras clave }\end{array}$ \\
\hline \multicolumn{2}{|c|}{ Próposito del Estudio } \\
\hline $\begin{array}{l}\text { El propósito de la investigación es claro; sin embargo, } \\
\text { solo se presenta de forma explícita en el resumen del } \\
\text { artículo y no se retoma al terminar la revisión teóri- } \\
\text { ca o antes de comenzar el método y en sí, ningún otro } \\
\text { momento del texto por lo que a lo largo de la lectura } \\
\text { se puede perder un poco. No se plantean preguntas de } \\
\text { investigación u objetivos específicos de forma explícita. } \\
\text { Debido a lo anterior el propósito y las preguntas tam- } \\
\text { poco se retoman explícitamente en los resultados y en } \\
\text { la discusión, aunque sí de forma implícita puesto que } \\
\text { todo lo reportado se vincula claramente con el propó- } \\
\text { sito planteado inicialmente. }\end{array}$ & $\begin{array}{l}\text { El propósito del estudio es claro, novedoso, está bien } \\
\text { fundamentado y es congruente con el método de es- } \\
\text { tudio planteado }\end{array}$ \\
\hline \multicolumn{2}{|c|}{$\begin{array}{ll}\text { Introducción } \\
\end{array}$} \\
\hline
\end{tabular}




\begin{tabular}{|c|c|}
\hline Revisor 1 & Revisor 2 \\
\hline $\begin{array}{l}\text { La introducción tiene muy buena estructura. Se presen- } \\
\text { tan las investigaciones previamente realizadas con gran } \\
\text { coherencia. Se vinculan directamente con el presente } \\
\text { estudio, el cual, queda bien situado en el campo del co- } \\
\text { nocimiento que le compete. El problema a estudiar está } \\
\text { muy bien delimitado, pero al igual que en el caso de la } \\
\text { pregunta de investigación, los objetivos específicos no } \\
\text { aparecen de forma explícita, por lo que sugiero que se } \\
\text { desarrollen con claridad para fortalecer este trabajo. }\end{array}$ & $\begin{array}{l}\text { En forma explícita, no se presenta ninguna hipótesis ni } \\
\text { se describen las variables a analizar. }\end{array}$ \\
\hline
\end{tabular}

\section{Método}

En el apartado de participantes podrían argumentar explícitamente que se buscaba conocer esta información de todos los estudiantes de esta carrera y modalidad, de modo que se cubriera a toda la población, por lo que se empleó un muestreo intencional (y hacer explícito el tipo de muestreo empleado). Lo menciono ya que no queda del todo claro al dar una primera lectura del texto y pareciera que se seleccionó un tamaño de la muestra específico. También considero necesario aclarar cómo se procesaron los datos, qué tipo de análisis se empleo, se da por supuesto que hubo un tratamiento de estadística descriptiva, pero no aclaran con qué software o medio; cómo procesaron los datos o con qué software pudieron hacer el acumulado, la identificación de frecuencias y porcentajes que presentan en la sección de resultados. Con respecto al instrumento, sugiero que desarrollen qué consideraron como bases fundamentales para su elaboración, si se apoyaron de la literatura previamente revisada al respecto o cómo llegaron a su construcción. También, valdría la pena señalar qué tipo de preguntas emplearon, si era abiertas, en escala likert, o de qué tipo. Finalmente considero necesario resaltar brevemente los aspectos de confidencialidad que tomaron en cuenta, si se presentó al inicio de la encuesta algún breve apartado que le indicara a los participantes que su participación era de forma anónima, si se escribió en el correo en el que se compartió la encuesta, o qué consideraciones tomaron en cuenta a la hora de elaborarla, de modo que les permitiera cuidar estos aspectos.

En forma explícita, no se señala el tipo de análisis de los datos en la parte del método ni de los criterios de medición de las variables. Tampoco se señala en forma explícita el tipo de estudios o de diseño. Sería conveniente agregar la generación en la que estaban inscritos los participantes (por ejemplo generación 2018-2021). Señala que el muestreo es por conveniencia pero cuando menciona en los resultados quienes respondieron, pareciera más bien voluntario, de acuerdo al texto metodológico en el que se apoya. 


\begin{tabular}{|c|c|}
\hline Revisor 1 & Revisor 2 \\
\hline \multicolumn{2}{|c|}{ Resultados } \\
\hline $\begin{array}{l}\text { La presentación de los resultados es muy clara y precisa } \\
\text { pues no solo consolidaron el análisis de los datos cuan- } \\
\text { titativos, también presentan las experiencias y percepcio- } \\
\text { nes de los participantes. Señalan similitudes, recurrencias } \\
\text { y diferencias entre ellos, lo que enriquece la investigación. } \\
\text { Una vez que hayan quedado explícitos los objetivos y pre- } \\
\text { guntas en el apartado anterior, la presentación de los resul- } \\
\text { tados tendrá aun más fortaleza y vínculo con los mismos. }\end{array}$ & $\begin{array}{l}\text { Me pareció un buen análisis y presentación de resultados, } \\
\text { tanto de los datos cuantitativos como los cualitativos. En } \\
\text { algunas partes, comienza la discusión de los resultados } \\
\text { en la sección de resultados y no en la de discusión. Se su- } \\
\text { giere respetar el formato propuesto para ello. Se sugiere } \\
\text { revisar el nombre y número de figuras y tablas. }\end{array}$ \\
\hline \multicolumn{2}{|c|}{ Discusión } \\
\hline $\begin{array}{l}\text { La discusión está muy bien elaborada y estructurada con } \\
\text { base en la presentación de resultados; es pertinente y deri- } \\
\text { vada de los mismos. Se vincula apropiadamente con la in- } \\
\text { vestigación previa y permite entender la manera en que este } \\
\text { estudio abona al campo del conocimiento que le compete. }\end{array}$ & No se señalan las limitaciones del estudio en forma explícita \\
\hline \multicolumn{2}{|c|}{ Conclusiones } \\
\hline $\begin{array}{l}\text { El apartado de conclusiones, al igual que el de discusión } \\
\text { está muy bien estructurado. Algo que le daría fortaleza } \\
\text { es que, una vez que hagan explícitos en el método las } \\
\text { preguntas y objetivos específicos, los retomen en este } \\
\text { apartado. De este modo podrán resaltar la forma en } \\
\text { que se ha dado respuesta a las preguntas y cumplimien- } \\
\text { to a los objetivos con base en los datos presentados. }\end{array}$ & En general son adecuadas \\
\hline \multicolumn{2}{|c|}{ Referencias } \\
\hline $\begin{array}{l}\text { Todas las referencias empleadas son pertinentes para } \\
\text { la investigación. Solo considero necesario verificar al- } \\
\text { gunas de ellas en las que se empleó el símbolo " } \& \text { " de } \\
\text { forma inapropiada. }\end{array}$ & $\begin{array}{l}\text { Faltan algunas referencias de las citas que se incluyen } \\
\text { en el manuscrito y hay algunos errores que se señalaron } \\
\text { en los documentos }\end{array}$ \\
\hline
\end{tabular}


